\title{
Successful endoscopic transpapillary gallbladder stenting using a new easily maneuverable guidewire: a report of two cases
}

Endoscopic transpapillary gallbladder drainage has a poor technical success rate $(80 \%-90 \%)[1-4]$. The technique is sometimes challenging when the guidewire cannot be advanced through the cystic duct into the gallbladder because of ductal tortuosity or obstruction [5] ( Fig.1). This report describes a new, easily maneuverable guidewire (approved by the review board of Nagoya City University Graduate School of Medical Sciences; approval No.46-18-0012), which was successfully advanced into the gallbladders of two patients in whom a conventional guidewire could not be advanced ( $\triangleright$ Fig. 2 , $\triangleright$ Video 1 ).

Case 1: an 83-year-old man developed epigastralgia caused by acute cholecystitis 3 days after percutaneous coronary intervention to treat acute coronary syndrome. As he was at risk of requiring anticoagulation therapy, percutaneous transhepatic gallbladder drainage was performed on the same day, and a choledocholithiasis was detected via cholangiography ( $\mathbf{F i g . 3}$ ). Then, 3 months later, after his heart condition had stabilized, we performed endoscopic choledocholithiasis extraction and endoscopic transpapillary gallbladder stenting (ETGS) to remove the percutaneous catheter and prevent future acute cholecystitis.

Case 2: a 65-year-old man was admitted with epigastralgia caused by recurrent acute cholecystitis; he was awaiting preventative cholecystectomy (\$ Fig.4). A new choledocholithiasis originating from the gallbladder was detected on computed tomography; we extracted it and then performed subsequent ETGS as a bridge to cholecystectomy.

In both cases, tortuous cystic ducts hindered the advancement of a regular guidewire, with "popping up" of its flexible tip portion ( $\triangleright$ Fig. 1). Therefore, we used the improved M-through guidewire

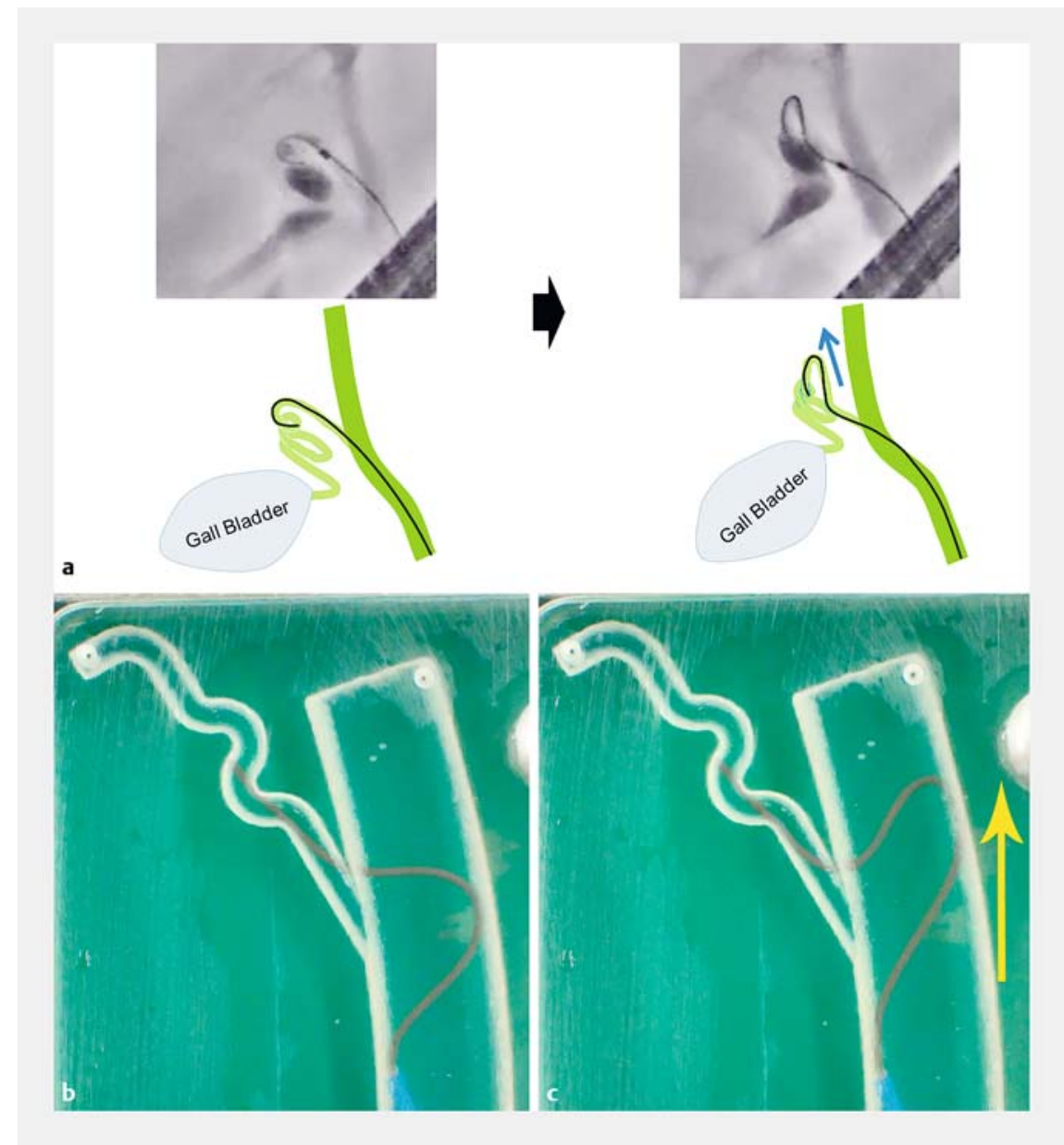

- Fig. 1 Difficult passage of a guidewire through the cystic duct into the gallbladder. Regular guidewires often fail to pass through the duct because of control difficulty with "popping up" of its flexible tip portion (blue and yellow arrows). a Fluoroscopic images and schematic diagrams. b, c Close-up photos of the flexible tip in a phantom model of the bile duct.

(ASAHI INTECC Corp., Seto, Japan), which was maneuvered easily and was successfully passed through both cystic ducts; we placed plastic stents along the guidewires. The new guidewire has an innovative tip allowing smooth tracking and easy maneuverability. This guidewire was passed rapidly through tortuous cystic ducts, followed by plastic stent placement in the gallbladder ( $>$ Fig. 5).
Endoscopy_UCTN_Code_TTT_1AR_2AK

Acknowledgments

The improved M-through guidewires were gifts from ASAHI INTECC Corp. 

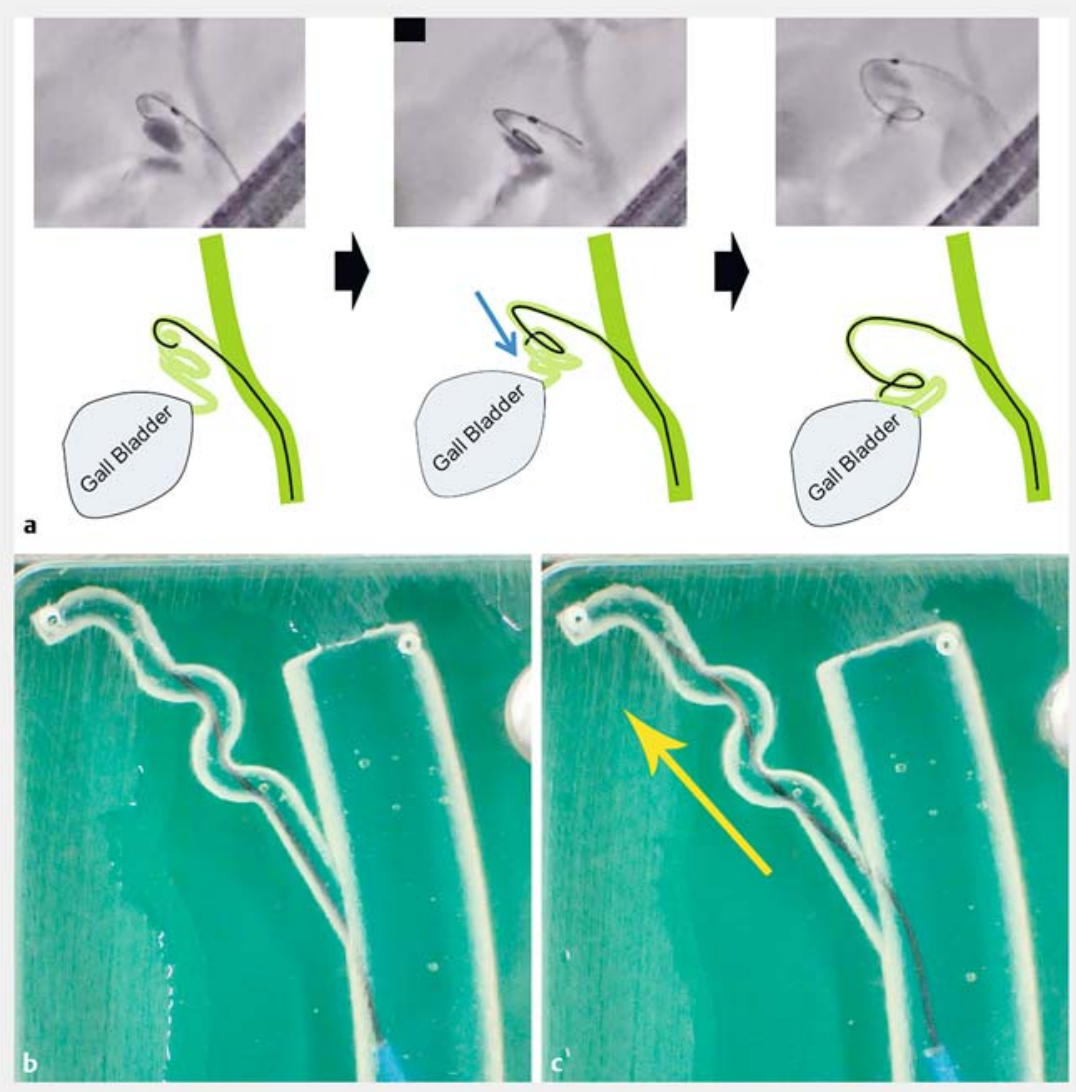

- Fig. 2 Improved passage of an M-through guidewire (ASAHI INTECC Corp., Seto, Japan) through the cystic duct into the gallbladder. The novel flexible tip portion avoids being popped up and allows smooth control of the guidewire during advancement through a tortuous cystic duct (blue and yellow arrows). a Fluoroscopic images and schematic diagrams. b, $\mathbf{c}$ Close-up photos of the flexible tip in a phantom model of the bile duct.
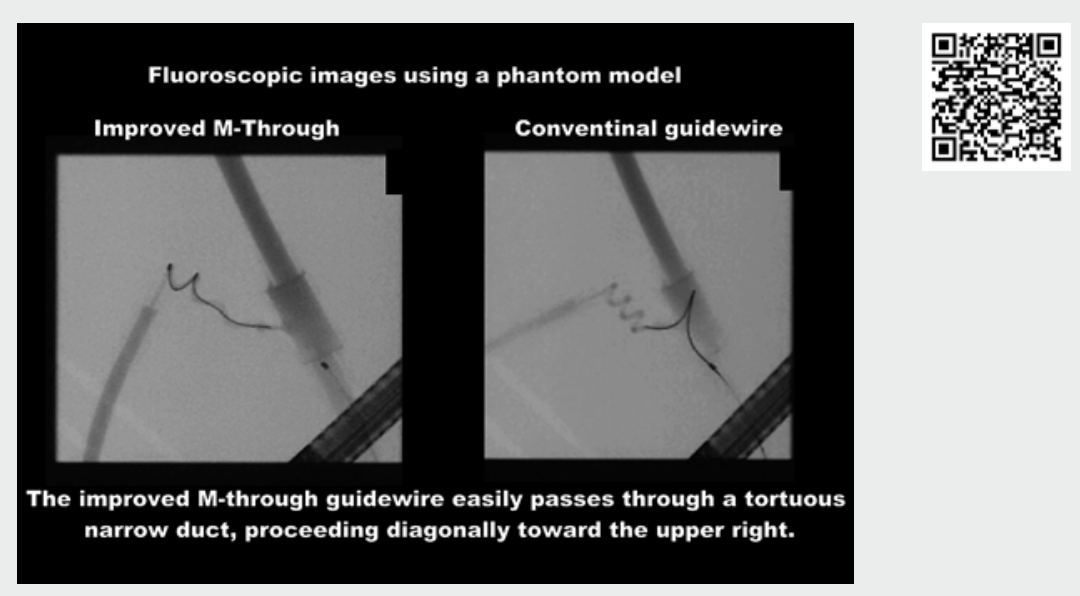

$\checkmark$ Video 1 Two cases of endoscopic transpapillary gallbladder stenting using a new easy maneuverable guidewire.

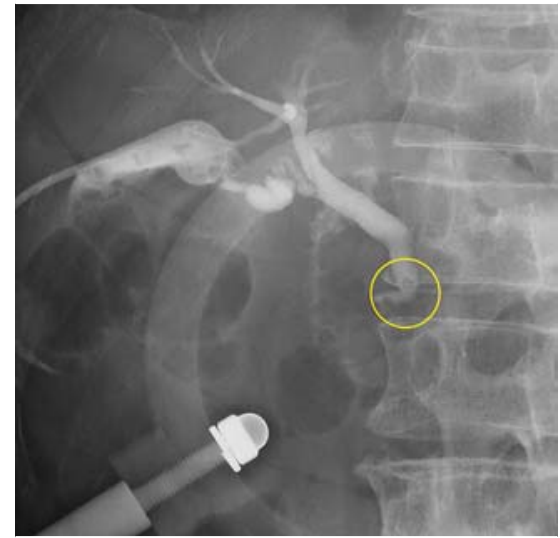

- Fig. 3 Case 1 (83-year-old man): cholangiography revealed a small choledocholithiasis that had originated from the gallbladder (yellow circle).

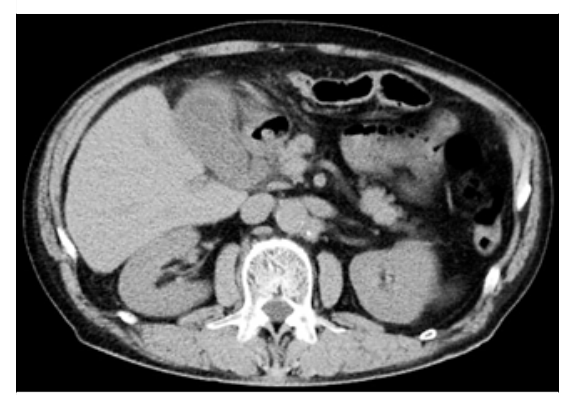

Pig. 4 Case 2 (65-year-old man): computed tomography revealed gallbladder swelling with wall thickening and pericholecystic fat stranding, suggestive of acute cholecystitis.

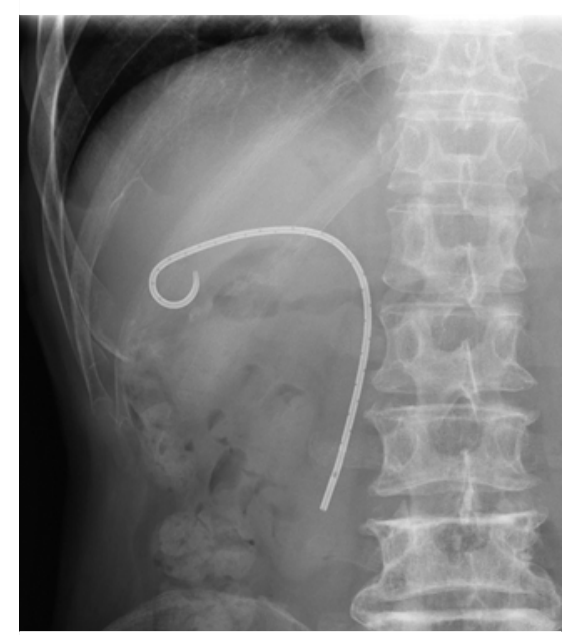

- Fig. 5 A fluoroscopic image obtained after performing endoscopic transpapillary gallbladder stenting in Case 1 . A $5 \mathrm{Fr} \times 13 \mathrm{~cm}$ single-pigtail stent (Gadelius Medical K. K., Sagamihara, Japan) was finally placed along the guidewire into the gallbladder. 
None

The authors

Katsuyuki Miyabe ${ }^{*}$ Akihisa Kato*, Go Asano, Yasuki Hori, Michihiro Yoshida, Itaru Naitoh, Kazuki Hayashi

Department of Gastroenterology and Metabolism, Nagoya City University Graduate School of Medical Sciences, Nagoya, Japan

\section{Corresponding author}

\section{Kazuki Hayashi, MD}

Department of Gastroenterology and Metabolism, Nagoya City University Graduate School of Medical Sciences, 1 Kawasumi, Mizuho-cho, Mizuho-ku Nagoya 467-8601, Japan

khayashi@med.nagoya-cu.ac.jp

\section{References}

[1] Itoi T, Coelho-Prabhu N, Baron TH. Endoscopic gallbladder drainage for management of acute cholecystitis. Gastrointest Endosc 2010; 71: 1038-1045

[2] Oh D, Song T], Cho DH et al. EUS-guided cholecystostomy versus endoscopic transpapillary cholecystostomy for acute cholecystitis in high-risk surgical patients. Gastrointest Endosc 2018; 10: 33011 - 33016

[3] Yang M], Yoo BM, Kim JH et al. Endoscopic naso-gallbladder drainage versus gallbladder stenting before cholecystectomy in patients with acute cholecystitis and a high suspicion of choledocholithiasis: a prospective randomised preliminary study. Scand J Gastroenterol 2016; 51: 472 - 478

[4] Itoi T, Kawakami H, Katanuma A et al. Endoscopic nasogallbladder tube or stent placement in acute cholecystitis: a preliminary prospective randomized trial in Japan (with videos). Gastrointest Endosc 2015; 81: $111-118$

[5] Widmer ], Alvarez P, Sharaiha RZ et al. Endoscopic gallbladder drainage for acute cholecystitis. Clin Endosc 2015; 48: 411 420

\section{Bibliography}

DOI https://doi.org/10.1055/a-0929-4645

Published online: 7.6.2019

Endoscopy 2019; 51: E349-E351

(c) Georg Thieme Verlag KG

Stuttgart · New York

ISSN 0013-726X

\section{ENDOSCOPY E-VIDEOS}

https://eref.thieme.de/e-videos

Endoscopy E-Videos is a free access online section, reporting 田: on interesting cases and new techniques in gastroenterological endoscopy. All papers include a high quality video and all contributions are freely accessible online.

This section has its own submission website at https://mc.manuscriptcentral.com/e-videos

* These authors contributed equally to this work. 